\title{
Entre o oficial e o alternativo em propostas curriculares: para além do hibridismo*
}

\author{
Reinaldo Matias Fleuri \\ Faculdade de Educação, Universidade Federal de Santa Catarina
}

Caminante, no hai camino,

el camino se hace al andar!

Antonio Machado

No debate que vimos desenvolvendo no grupo de trabalho educação popular da ANPEd, constatamos que a globalização representa uma palavra-chave de retóricas estratégicas, que constituem um meticuloso jogo político em que os discursos vão instituindo proposições quase unanimemente inquestionáveis. Globalizar pode significar homogeneizar, diluindo identidades e apagando as marcas das culturas ditas inferiores, das

*Este texto representa a sistematização das anotações feitas por ocasião do debate na sessão especial "Propostas curriculares: entre o oficial e o alternativo", promovida pelos grupos de trabalho currículo, educação popular e educação fundamental, na $23^{\mathrm{a}}$ Reunião Anual da ANPEd, realizada de 24 a 28 de setembro de 2000, em Caxambu (MG). A versão inicial do texto foi divulgada na página da ANPEd na Internet. Cleonice Tomazetti participou como colaboradora na elaboração deste artigo. raças, etnias, gêneros, linguagens, religiões, grupos etc. que, segundo a lógica das narrativas hegemônicas, foram identificadas como portadoras de deficiências, inclusive de racionalidade. Assim, "neste final de milênio, parece que não se trata mais apenas de lutar pela sobrevivência física, material, dos grupos marginalizados, trata-se agora de lutar pela própria possibilidade de sua existência no campo do simbólico" (Costa, 1998b, p. 9), compreendendo suas culturas como sistemas originais de viver e pensar.

A cultura representa justamente este conjunto de "práticas e instituições dedicadas à administração, renovação e reestruturação do sentido" (Canclini, 1983, p. 29). Entendemos "sentido" como a identificação simbólica, por parte de um ator social, da finalidade da ação praticada por tal ator. Nesta perspectiva, podemos entender "as escolas e seus currículos como territórios de produção, circulação e consolidação de significados, como espaços privilegiados de concretização da política da identidade. Quem tem força nessa política impõe ao mundo suas representações, o universo simbólico de sua cultura particular" (Costa, 1998a, p. 38). 
Entre os processos recentes de reformulação curricular, encontra-se o movimento da Constituinte Escolar desencadeado, em abril de 1999, pelo Governo do estado do Rio Grande do Sul. Seu objetivo é promover a construção da democracia participativa. Junto com outros instrumentos, como o orçamento participativo, pretende promover a participação popular na definição e no controle de políticas públicas. O movimento é conduzido pela Secretaria de Educação, que abre espaços para a participação das comunidades escolares (educadores, pais, estudantes e funcionários), de movimentos sociais populares, de instituições de ensino superior e instituições do poder público. Neste sentido, considera-se que "a Constituinte Escolar vem se consolidando enquanto movimento político-pedagógico de resgate/apropriação da educação e da escola pública pela comunidade escolar e pelos setores populares" (Estado/RS, 2000a, p. 4).

A Constituinte Escolar do Rio Grande do Sul pode ser vista, então, como campo de "produção, circulação e consolidação de significados", ou, numa perspectiva mais dinâmica, como campo cultural de práticas dedicadas à "administração, renovação e reestruturação do sentido", desenvolvido pela interação entre diferentes sujeitos, agentes institucionais e movimentos sociais, entre seus diferentes contextos culturais, na luta por reconhecerem e serem reconhecidos, em suas identidades, pelos sentidos que produzem social e historicamente.

Que sentidos estão sendo produzidos ou reestruturados neste processo? Ou melhor, que lógicas de elaboração e de interpelação de sentidos estão emergindo e se confrontando?

Sandra Corazza levanta uma instigante questão a este respeito. Desafia-nos a encarar as similaridades e as diferenças entre a proposta curricular do governo petista do Rio Grande do Sul (1999-2002), que está sendo elaborada através da Constituinte Escolar, e a do Governo Federal, que foi apresentada em 1997 por meio dos Parâmetros Curriculares Nacionais. Mediante arguta análise dos documentos e brilhante argumentação, ela defende que "não conseguimos legitimar, nem consolidar políticas, currículos, propostas pedagógicas, ou discursos 'alternativos"” porque "perdemos o rumo, os limites e o diferencial, que nos permitiam distinguir o que era 'oficial' do que era 'alternativo"". Sandra demonstra sua tese mediante a explicitação de similaridades discursivas entre textos dos Parâmetros Curriculares Nacionais e do Movimento Constituinte Escolar do Estado do Rio Grande do Sul. Evidenciou-se um hibridismo dos dois discursos. E nos encontramos, nus, horrorizados diante do fato de "que nossos currículos 'alternativos', produzidos em quase trinta anos de trabalho nas organizações nãogovernamentais, sindicatos, movimentos sociais, escolas, vilas, universidades, estão lá, presentes e encravados no Currículo Nacional. E que este, 'oficial', está também aqui, nos currículos que organizamos e implementamos, e que ensinamos a organizar e a implementar".

O "horror" nos assalta ao descobrirmos que as propostas educacionais construídas em oposição ao sistema capitalista e à ideologia liberal encontram-se agora "globalizada", "neoliberalizada". Além disso, as tentativas de elaborar novas alternativas de currículo não conseguem produzir um discurso diferente do hegemônico.

Mas o jogo argumentativo proposto por Sandra não termina com esta constatação, pois conclui com um novo desafio: "importa perguntar se tudo o que vimos, até agora, nas propostas curriculares, é tudo o que pode ser visto, e se tudo o que dissemos é tudo o que pode ser dito. Fabricar outros óculos e outra linguagem para ver e dizer as coisas e as palavras de 'nossos' currículos. Sabendo que, se o seu traçado chegou até aqui, assim, é porque, como tal, foi criado. Se foi criado assim, poderá ser traçado de outros modos".

\section{O jogo e o paradoxo}

Vou retomar o jogo a partir deste ponto, limitando-me a dar um passo de formiguinha. Focalizarei algumas questões a propósito do oficial e do alternativo na Constituinte Escolar do Estado do Rio Grande do Sul. Retomarei algumas considerações elaboradas nos debates que vimos desenvolvendo no contexto do gru- 
po de trabalho educação popular da ANPEd. E, a partir destas considerações, tentarei formular algumas questões a respeito dos sujeitos e dos processos desenvolvidos pela Constituinte Escolar do Rio Grande do Sul. Fazer perguntas talvez seja um modo de orientar nossos olhares para "ver o que ainda não vimos". Talvez seja um passo necessário para elaborar nossa linguagem para "dizer o que ainda não foi dito".

Tentemos iniciar esta discussão a partir de uma metáfora. O matemático E. A. Abbott narra - em Flatlândia (apud Mele, 1994, p. 219) - uma historieta ainda hoje pouco conhecida. Descreve um país imaginário onde não se conhece a terceira dimensão, onde a vida se desenvolve em um único grande plano, e habitar em um espaço significa, por definição, não poder conhecê-lo. A narração começa quando o protagonista, A. Square (literalmente, Um Quadrado), sonhou com a Linealândia. Neste país, tudo acontece em uma única dimensão, a da linha. Observando a partir do exterior, A. Square pode perceber muito bem a "linearidade" da vida naquele país, percepção esta impossível para seus habitantes (os segmentos e os pontos). Do diálogo que mantém com estes, A. Square começa a questionar os limites do ponto de vista deles, que não admite a possibilidade da existência de uma segunda dimensão. E com isso, A. Square passa a questionar os limites também do próprio ponto de vista, a partir do qual era impossível conceber uma terceira dimensão. E assim este sonho o prepara para o encontro desconcertante com uma outra dimensão. Sentiu uma grande resistência a aceitar a existência de uma terceira dimensão. Mas, tendo entendido que a construção daquilo que chamamos de realidade é conduzida pela relação entre o espaço, a percepção e a linguagem, A. Square sente-se livre para aceitar a existência de uma quarta, uma quinta e talvez infinitas dimensões. Mesmo se não está ainda materialmente em condições de representá-las, pode no entanto intuir sua presença e isto prepara seus sentidos para possivelmente percebê-las e conhecê-las. E a crise de A. Square começou quando seu sobrinho lhe fez notar pela primeira vez que $3^{2}$ significa 9 e quer dizer também a superfície de um quadrado com $3 \mathrm{~cm}$ de lado. Então, talvez $3^{3}$ signifique não apenas 27 , mas deveria ter também algum significado geométrico. A. Square, irritado, responde ao sobrinho que isto seria impossível, porque a "geometria tem apenas duas dimensões". E manda o menino ir dormir. A reação abrupta do velho não resultava da falta de informações científicas (pois era um reconhecido sábio). O fato é que a observação aguda de seu sobrinho introduz, no mundo com o qual A. Square se identifica, a ameaça de um paradoxo.

Paradoxo é uma contradição lógica que, se não resolvida, coloca em cheque toda a estrutura lógica da argumentação que a gerou. A teoria dos tipos lógicos (formulada por Bertrand Russel e Alfred North Whitehead na famosa obra Principia Mathematica, 1910) afirma: “quando uma sucessão de proposições gera um paradoxo, a estrutura dos axiomas, teoremas, [...] em seu conjunto, empregada para gerar aquele paradoxo é por isto mesmo negada e anulada".

Acredito que nosso "espanto" ante a constatação do "hibridismo" das propostas curriculares entre o of $i$ cial e o alternativo evidencia um paradoxo, ou seja, coloca em cheque a lógica segundo a qual estamos entendendo esta relação.

Oficial significa um documento ou ato proposto por autoridade legalmente constituída, ou dela emanado. Já o termo alternativo, no sentido que nos interessa neste debate, refere-se a algo "que não está ligado aos interesses ou tendências políticas dominantes", como, por exemplo, imprensa alternativa, movimentos sociais alternativos. ${ }^{1}$

A relação de identidade entre os dois termos, oficial e alternativo, torna-se um contra-senso se for interpretada a partir de uma lógica binária, e de oposição. Um elemento não pode ser simultaneamente o seu contrário! Segundo a lógica binária pressupomos a relação entre um único elemento com outro elemento também único. A simples observação dos fatos evi-

${ }^{1} \mathrm{O}$ termo "alternativo" pode indicar, também, algo que se diz ou se faz com alternação, que vem ora um, ora outro, no sentido de alternado. Ou então, diz-se das coisas de que se pode escolher a que mais convenha. 
dencia que não existe um oficial e um alternativo, mas muitos diferentes processos oficiais e uma variedade imensa de tendências alternativas. Assim, pressupondo a multiplicidade de elementos que compõem estes dois campos, podemos entender que haja simultaneamente elementos do campo alternativo que se identificam com elementos do campo oficial, ao mesmo tempo em que haja elementos contrários dentro dos mesmos campos.

Também a lógica de oposição não é suficiente para explicar tal realidade, pois as propostas oficiais não são explicáveis apenas como negação daquelas alternativas, nem vice-versa. Um elemento se explica não apenas pela negação do outro, mas pela afirmação de sua singularidade.

O paradoxo remete-nos a elaborar uma lógica de interpretação que permita pensar simultaneamente a multiplicidade de termos e de interações entre eles. Trata-se de se explicitar a lógica que permite compreender simultaneamente a articulação entre a unidade do conjunto e a diversidade de elementos que o constituem.

Este é um problema de caráter epistemológico. Epistemologia, em sentido amplo, significa conjunto de premissas que sustentam nossos modos de fazer distinções, de segmentar os eventos, de dar sentido ao mundo (Bateson, 1976, 1986). Os tipos de distinção normalmente assumidos são baseados na oposição: ou/ou. Esta forma de pensar nos leva fatalmente a escolher um pólo, excluindo ou submetendo todos os outros. Mas numa outra perspectiva epistemológica, a complexa (chamada também de sistêmica, ecológica), são propostas "premissas diferentes para nossos sistemas de distinção: uma epistemologia da conexão: ele. As oposições não devem ser (ingenuamente) eliminadas, mas é indispensável descobrir a estrutura que possa conectálas, o contexto comunicativo que possa coligá-las. [...] As conexões, dentro de um novo contexto, permitem superar as oposições; e isto não tanto porque as contradições desaparecem, mas porque se produzem mudanças, evoluções, que envolvem todos os membros em oposição" (Severi \& Zanelli, 1990, p. 31-32).

Neste sentido, é preciso "considerar como correlacionados (pensar contemporaneamente) tanto a dife- renciação das identidades quanto as estruturas de conexão (os contextos comunicativos)" (Severi \& Zanelli, 1990, p. 39). A complexidade implica, pois, a relação entre contextos que se tecem juntos, desafiando-nos a trabalhar com a incerteza e com um pensamento multidimensional.

O paradoxo do hibridismo entre oficial e alternativo no discurso curricular não se resolve, pois, mediante a explicação apenas de suas distinções ou oposições, mas também mediante a explicitação de suas interconexões, ou seja, o desafio é o de focalizar simultaneamente a multiplicidade de ações, de finalidades, de interpretações, de lógicas e categorias de interpretação, desenvolvidas por diferentes sujeitos, em múltiplas relações que criam, sustentam e modificam múltiplos contextos sociais que configuram os sentidos de nossas ações. Tal desafio nos remete à necessidade de um "salto lógico" que nos coloque em uma perspectiva teórica que torne possível compreender as relações entre diferentes dimensões das práticas humanas e entre diferentes pontos de vista (Valla, 1998a). Nesta perspectiva, como propõe Morin, "o método da complexidade nos orienta a pensar sem nunca fechar os conceitos, a quebrar as esferas fechadas, a restabelecer as articulações entre o que se encontra dividido, a nos esforçar para compreender a multidimensionalidade, a pensar com a singularidade, com a localidade, com a temporalidade, a jamais esquecer as totalidades integradoras. [...] a complexidade reside justamente nisto: na conjunção de conceitos que se combatem reciprocamente" (1985, p. 59-60).

\section{Caminante!}

Sandra Corazza afirma que a formulação do discurso curricular tem "uma função governamental, que inscreve formas calculadas de ação sobre as condutas e relações de cada indivíduo e da população, para atingir certos objetivos sociais e políticos. Um discurso vinculado a tecnologias de governo, que habilitam os indivíduos a viverem tipos particulares de experiências, e a se tornarem determinados tipos de sujeitos". 
O discurso orienta e condiciona as ações e relações dos sujeitos. Em contrapartida, o discurso é produzido por sujeitos em relação. Por isso, ao questionar o discurso produzido pela Constituinte Escolar do Rio Grande do Sul, é preciso questionar também os sujeitos que produzem tal prática discursiva.

Quem são os sujeitos promotores deste movimento? Está claro que é a Secretaria de Educação do Governo do Estado, a principal articuladora e condutora do processo constituinte, juntamente com suas trinta Coordenadorias Regionais de Educação.

A grande novidade na concepção dos sujeitos envolvidos no processo constituinte é a atenção aos movimentos sociais populares. ${ }^{2}$ Quem são esses novos protagonistas convidados a entrar no cenário político? A partir da década de 1990, os movimentos sociais no Brasil passaram por uma profunda crise em sua concepção e prática política. Os movimentos sociais no Brasil comparados à década anterior continuaram sofrendo profundo retrocesso nas suas grandes mobilizações e conquistas por parte das classes trabalhadoras. Somada a um processo de mudança profunda no capitalismo, a crise dos movimentos sindicais e populares veio à tona também no Brasil, deixando a esquerda atônita.

Elisa Pereira Gonsalves identifica tal perplexidade em um grafite nos muros da cidade de Bogotá: "Cuando tenía casi todas las respuestas me cambiaron las preguntas!" (Quando já dispunha de quase todas as respostas, mudaram as perguntas!). Gonsalves con-

2 “O capitalismo ocorrido após a Revolução Industrial e com o avanço e a concentração tecnológica, com a especulação financeira, a exploração e o desrespeito aos direitos, mesmo os institucionais, levaram a uma situação de miserabilidade setores tão significativos da população, que o modelo de regulação social não mais sustenta e mantém a submissão do conjunto da população. É neste cenário que novos sujeitos políticos se constroem, enquanto agentes de pressão por mudança: os sujeitos coletivos, que passam a buscar o direito de reivindicar direitos, que se propõem a construir uma sociedade que responda aos interesses dos trabalhadores. Esses sujeitos são os Movimentos Sociais Populares" (ESTADO/RS, 2000a, p. 7). sidera que "a questão da globalização se impõe cada vez mais como realidade histórica, desafiando as construções teóricas clássicas. A dialética da história está entrando em novo ciclo e o final do século XX tem colocado problemas inauditos para os quais os conceitos e as interpretações de hoje são insuficientes. Assiste-se, portanto, em nível mundial, a uma reorganização da sociedade, de seus atores e das relações na qual novas condições históricas transformam as formas de pensar, conhecer, dominar e resistir" (1997, p. 1).

Tal crise oportuniza a crítica ao marxismo e muitos grupos adotam uma "nova estratégia substitutiva da perspectiva revolucionária marxista", como aponta Daniel Álvares Rodrigues, em um trabalho apresentado no grupo de trabalho educação popular, em 1997. Mas, na avaliação deste autor, "apesar de apresentarse como uma atualização à luta política, a crítica ao marxismo representa um recuo na proposição de ruptura no enfrentamento ao capitalismo. A teoria marxista contém elementos que possibilitam o entendimento da força do projeto neoliberal em sua essência: a concentração e centralização das riquezas produzidas, ou seja, a potencialização de sua organização e os objetivos do capital. Mesmo considerando suas inúmeras interpretações, o marxismo caracteriza-se, a nosso ver, como uma forte inspiração para a luta revolucionária a fim de dar consequiência à luta pela hegemonia na nossa sociedade por parte das classes trabalhadoras" (1997, p. 14). Esclarece, entretanto, que não se trata de simplisticamente "separar, de um lado, marxistas e de outro, os não-marxistas. Na verdade, mesmo não negando a existência dessa diferença, ela deve ser fundamentada nas forças que percebem a luta classista sob a óptica revolucionária ainda como uma premência imposta pelo próprio capitalismo. Foi exatamente enfrentando posições reformistas que se possibilitou a unificação dos setores marxistas fora do âmbito dos Partidos Comunistas, com setores humanistas da Igreja junto aos movimentos sociais 'autênticos' ou combativos. Esses conseguiram construir um processo sob uma outra perspectiva da luta política, definindo-se enquanto movimento classista, de massas, democrático, fundamentalmente anticapitalista, a 
partir de uma perspectiva revolucionária, hegemonizadas pela interpretação materialista dialética da sociedade" (Rodrigues, 1997, p. 14).

Assim, reconhece-se que a teoria marxista mantém sua eficácia explicativa do processo de concentração e de centralização das riquezas produzidas nos sistema econômico capitalista globalizado. Valorizase também, nesta perspectiva, a luta classista sob a óptica revolucionária. Mas verifica-se que, no processo de crise dos grandes movimentos sociais, outras faces e dimensões dos movimentos populares vêm à tona.

Adir da Luz Almeida, retomando o estudo de Cecília Coimbra, explica que mesmo antes do período de distensão "lenta, gradual e segura" de Geisel e de "abertura" promovida pelo governo Figueiredo, novas práticas sociais foram sendo geradas. "Práticas que rechaçam os movimentos tradicionalmente instituídos, que politizam o cotidiano dos lugares de trabalho e moradia, que inventam novas formas de fazer política" (Coimbra, 1992, p. 36, apud Almeida, 1994).

Trata-se de novos sujeitos coletivos, cujas identidades não é simples definir. Segundo Sader, sujeitos coletivos se referem a "pluralidades de sujeitos, cujas identidades são resultados de suas interações em processo de reconhecimento recíproco, e cujas posições são mutáveis e intercambiáveis. As posições dos diferentes sujeitos são desiguais e hierarquizáveis, mas essa ordenação não é anterior aos acontecimentos, mas resultados deles. E sobretudo, a racionalidade da situação não se encontra na consciência de um ator privilegiado, mas é, também, resultado do encontro das várias estratégias" (Sader apud Fantini, 1996, p. 16).

As lutas cotidianas por direitos básicos de acesso à saúde, à moradia, a saneamento, educação engendram novas formas de fazer política e de construir a democracia, pois "se esta talvez se expresse em nível das grandes organizações políticas e sociais, ela só se consolida, só ganha consistência se existir no nível da subjetividade dos indivíduos e dos grupos, em todos os níveis moleculares, novas atitudes, novas sensibilidades, novas práxis, que impeçam a volta das velhas estruturas" (Guattari e Rolnik apud Almeida, 1994, p. 7).
Adir Almeida contesta a idéia de que tais movimentos sejam fragmentadores da realidade e de que, dessa forma, produziriam apoliticismo. Afirma, ao contrário, que "representam formas de resistência e rejeição àqueles que, pertencentes a partido político ou ao poder público, vêem esses movimentos como mera correia de transmissão de suas propostas [...] Coloca-se para o intelectual que trabalha com educação popular o desafio e a tarefa de buscar outros referenciais teóricos que rompam, definitivamente, com a forte influência iluminista que permeou e permeia muitas de suas ações junto aos grupos subalternizados" (1994, p. 7).

Tais considerações nos levam a buscar compreender mais precisamente: quem são os interlocutores da Secretaria da Educação do Estado e como eles são reconhecidos?

Os sujeitos coletivos são identificados e acolhidos pela Secretaria de Educação a partir de algumas categorias tradicionalmente consagradas: membros das comunidades escolares (educadores, pais, estudantes e funcionários), de movimentos sociais populares, de Instituições de Ensino Superior e Instituições do Poder Público.

É importante ter claro, em primeiro lugar: que grupos sociais não são incluídos nestas categorias? (organizações empresariais, os grupos marginais, organizações religiosas, associações recreativas e mesmo organizações de trabalhadores que divergem da proposta em andamento).

Em segundo lugar, quem são os incluídos entre os interlocutores? Qual a proporção [numérica] dos participantes das diferentes categorias? (Haverá uma predominância de professores, sobre os estudantes pais e funcionários? Quantos e quais movimentos sociais populares estão envolvidos no processo? Quantas e quais instituições de ensino superior e de poder público estão interferindo no processo constituinte?)

Em terceiro lugar, que grau de representatividade ou organicidade estes participantes mantém com seus grupos de referência? (Que propostas defendem? Que relações têm com os interesses objetivos dos grupos representados? Em que medida tais interesses são diferentes ou antagônicos?) 
Enfim, é importante considerar a complexidade constitutiva dos sujeitos, e de seus respectivos contextos, que interagem na Constituinte Escolar. Os diferentes vínculos, as diferentes representações e as diferentes opções, assumidas pelos participantes de uma comunidade ou de um movimento social, são determinantes da dinâmica e dos sentidos que configuram a vida dessa comunidade e a evolução desse movimento. Assim, na comunidade escolar, como no processo de reformulação curricular, os participantes são identificados como professores e funcionários, alunos e seus responsáveis, exclusivamente a partir de sua vinculação à instituição escolar. Mas os sentidos das ações que estes sujeitos constróem na prática escolar adquirem consistência também por seus diferentes vínculos sociais (a comunidades religiosas, sindicais, desportivas, de bairro etc.), por sua identificação com diferentes representações sociais (negro, de origem, homem, mulher, jovem, velho, portador de características particulares etc.), por suas opções (político-partidárias, familiares, sexuais, profissionais etc.). A trama de sentidos que institui a vida da escola resulta da interação entre os múltiplos sujeitos, sendo que cada sujeito se constitui por identidade múltipla. Assim, o mesmo "funcionário" - que na escola interage com o "aluno", o "professor", o "pai" - se identifica como homem ou mulher, velho ou jovem, caboclo ou de origem, gaúcho, desportista, religioso... Tal complexidade subjetiva e coletiva precisa, pois, ser considerada para se compreender a intensidade dos significados desenvolvidos em um processo de reformulação curricular.

\section{No hai camino}

Identificar e reconhecer os agentes e interlocutores é fundamental para se ter clareza das possibilidades reais da "democracia participativa" que pretende que "todos participem efetivamente das decisões tomadas para o conjunto da sociedade". É preciso que todos saibam quem efetivamente é reconhecido como integrante deste conjunto de todos. Do contrário, escamoteiam-se conflitos e, sobretudo, acobertam-se disposi- tivos normalizantes que sujeitam todos a processos de hierarquização e exclusão.

Mas a dificuldade maior é a de entender o que os diferentes grupos constitutivos dos movimentos populares estão realmente querendo propor. Segundo José de Souza Martins (1989), uma dificuldade dos grupos, partidos e igrejas reside em não reconhecer os "sinais" da "libertação": "não são os pobres que estão enfrentando dificuldades para romper as cadeias de seu cativeiro político, ideológico e, também, espiritual. São os políticos, os intelectuais, os missionários da emancipação, isto é, os grupos de mediação, que não estão conseguindo interpretar essas transformações, por insuficiência de seus esquemas teóricos e por dogmatismo de suas orientações políticas" (p. 14-15).

A crise dos grupos de mediação dos movimentos sociais deu início a um profícuo debate no grupo de trabalho educação popular da ANPEd sobre a dificuldade que os profissionais e intelectuais têm de compreender o que as classes populares estão querendo lhes dizer. Para Valla (1994), esta dificuldade está relacionada, de um lado, com o preconceito de que as pessoas "humildes, pobres, moradoras da periferia" sejam incapazes de produzir um conhecimento válido e tomar iniciativas coerentes, de outro lado, com a desconsideração da diversidade de grupos sociais, constituída a partir de diferentes raízes culturais e contextos sociais, que são entendidos sob o conceito de "classes subalternas".

O que se coloca em questão é a pressuposição de que "as idéias de uma época têm sua origem com as elites, as classes superiores, e que a sua difusão chega às classes subalternas de uma forma mecânica, sofrendo deterioração e sendo deformadas na medida em que são assimiladas pelas classes subalternas" (Valla 1994, citando Ginzburg, 1987). Neste sentido, "a cultura popular dever ser pensada como cultura, como conhecimento acumulado, sistematizado, interpretativo e explicativo, e não como cultura barbarizada, forma decaída da cultura hegemônica, mera e pobre expressão do particular" (Martins apud Valla, 1994, p. 10).

Mais propriamente, é preciso reconhecer as culturas populares, no plural, que constituem as diferen- 
tes formas de organização social e de interpretação da realidade construídas pelos diferentes grupos sociais que constituem as chamadas “classes subalternas". São culturas, com representações sociais e visões de mundo específicas, elaboradas segundo lógicas e categorias próprias. Ao ignorá-las ou desqualificá-las, os intelectuais e operadores sociais correm o risco de não entendê-las, de invalidar estes saberes e reforçar a trama de poder que em nossa sociedade subjuga estas culturas.

Tais considerações estimulam-nos a perguntar que referenciais teórico-metodológicos estão sendo utilizados na busca de entender o que os movimentos sociais populares estão propondo para o sistema público de educação?

\section{El camino se hace al andar}

A organização do processo da Constituinte Escolar no Estado do Rio Grande do Sul baseia-se em uma clara opção pela concepção dialética de conhecimento e pela metodologia de Pesquisa Participante. Esta se caracteriza por privilegiar o "trabalho com a camada social historicamente excluída dos processos econômicos, sociais, culturais" no sentido de favorecer "a participação das camadas populares como sujeitos de um processo de produção de conhecimento e, ao mesmo tempo, de definições de políticas públicas"; propõe desenvolver uma prática "articulada de educação, investigação e participação social, como momentos de um processo de análise das contradições que explicam os determinantes estruturais da realidade imediata que está sendo analisada"; tal elaboração baseia-se no trabalho de "grupos organizados, que formulem propostas práticas de intervenção na realidade que está sendo investigada, na perspectiva de sua efetiva transformação" (Estado/RS, 2000a, p. 11 e 12).

Coerente com esta opção metodológica, o processo da Constituinte Escolar do Rio Grande do Sul vem sendo conduzido em cinco momentos articulados. O primeiro momento consistiu na elaboração da proposta e lançamento da Constituinte em abril de 1999. Com ampla participação das comunidades escolares e re- presentações da sociedade civil, a Secretaria de Educação promoveu o "Estudo da Realidade" e o "Resgate de Práticas Pedagógicas". Neste segundo momento, "cada comunidade" foi convidada a refletir sobre "o seu fazer cotidiano e histórico" e identificar "os principais conflitos e dificuldades nele existentes". A partir do elenco das "práticas", "critérios", "dificuldades/ conflitos", "temáticas" e "temas" elaborado pela Secretaria de Educação e suas 30 Coordenadorias Regionais de Educação, foram escolhidos "25 Temas”, articulados em "4 Temáticas, para serem aprofundados".

O terceiro momento da Constituinte Escolar, denominado “Aprofundamento das Temáticas", realizouse em 2000, com "a devolução da sistematização do $2^{\circ}$ Momento e discussão dos Temas e Temáticas", por meio do Texto base para as pré-conferências municipais/micro-regionais da Educação (Estado/RS, 2000d). Este documento resulta "da sistematização do 'Aprofundamento [...]', realizado pelas escolas, passando por 31 Seminários Regionais de Sistematização nas Delegacias de Educação e na Secretaria da Educação/RS e por uma sistematização em nível estadual". O texto tentou reunir "o conjunto das elaborações e proposições da comunidade escolar em todo o Estado", e foi discutido nas pré-conferências municipais, microrregionais e regionais.

Já o quarto momento da Constituinte Escolar desenvolvido na "Conferência Estadual de Educação", ocorrida em Porto Alegre, de 24 a 26 de agosto de 2000 - produziu a "Definição dos Princípios e Diretrizes". Participaram desta Conferência "integrantes da comunidade escolar (pais, alunos, professores e funcionários), dos movimentos popular e sindical, das instituições de ensino, dos órgãos públicos, das organizações não governamentais, dos Fóruns setoriais, demais segmentos da sociedade civil, autoridades, convidados oficiais e observadores" (Estado/RS, 2000c, p. 8).

A partir da definição dos Princípios e Diretrizes para a Educação Pública Estadual (cf. Estado/RS, 2000f), vem sendo desenvolvido o quinto momento: reconstrução dos projetos político-pedagógicos das diferentes instâncias da Secretaria da Educação (Esco- 
las, Coordenadorias Regionais de Educação e Secretaria da Educação).

Sandra Corazza ressalta a nítida diferença entre o processo de formulação dos Parâmetros Curriculares Nacionais e o da Constituinte Escolar do Rio Grande do Sul. Esta última evidentemente envolve movimentos sociais muito mais representativos dos que foram envolvidos na elaboração dos PCNs. Por isso mesmo, a autora mostra sua estranheza diante do fato de que as duas propostas, produzidas por processos de elaboração tão distintos, apresentem resultados discursivos tão similares!

Tal estranheza poderia ser relativizada, uma vez que os próprios Parâmetros Curriculares Nacionais, por sua vez, incorporam aspectos de propostas curriculares desenvolvidas precedentemente na primeira metade dos anos 1990 durante a gestão de partidos de esquerda, como foram os casos de São Paulo, Belo Horizonte, Rio de Janeiro, Porto Alegre (Barreto, 1998, p. 5-42). Embora os significados dos PCNs se configurem no contexto da política do Governo Federal, incorporam ambivalentemente sentidos elaborados a partir de outros contextos e outras intencionalidades. Daí práticas diferentes podem a eles se referenciar de modo ambivalente.

Entretanto, os significados principais da Constituinte Escolar do Rio Grande do Sul talvez tenham de ser buscados mesmo é no processo e não apenas no seu resultado discursivo. João Guimarães Rosa é chamado em testemunha: "Digo: o real não está na saída nem na chegada: ele se dispõe para a gente é no meio da travessia" (apud Estado/RS, 2000a, p. 10).

Nesta perspectiva, pode-se discutir as possibilidades e os limites da pesquisa participante para sustentar e promover a "travessia" proposta pelo movimento Constituinte.

Entre os trabalhos do grupo de trabalho educação popular da ANPEd que problematizam e discutem as metodologias de Pesquisa Participante, encontra-se o de Eymard de Vasconcelos (1998). Estudando os significados e as críticas elaboradas a propósito da pesquisa participante, Vasconcelos alerta para "alguns cuidados metodológicos que precisam ser tomados" (p. 18), ${ }^{3}$ que nos orientam a questionar: Quais os diferentes instrumentos metodológicos de análise da realidade estão sendo utilizados no processo constituinte? Como está sendo relacionada a diversidade dos resultados obtidos com sínteses teóricas globalizantes? Que entendimentos estão sendo elaborados a respeito das dimensões inconscientes, míticas e religiosas dos atores sociais envolvidos? Que motivações e projetos utópicos estão mobilizando os pesquisadores e os atores sociais? Que outras leituras da realidade estão emergindo e como os pesquisadores lidam com elas? Como se articula a militância e a pesquisa?

No processo de elaboração teórica, o papel e a postura dos pesquisadores são determinantes. Mas Valla afirma: "se a referência para o saber é o profis-

3 "Antes de desencanto, a Nova Era pode significar desafio. Assim, o que significa pesquisar em educação popular neste tempo de pós-modernidade? Alguns cuidados metodológicos precisam ser tomados.

a) diversificação dos instrumentos metodológicos de análise da realidade popular. Vêm sendo muito mais valorizados os instrumentos da Antropologia e da análise de discurso.

b) Não exigência de uma correlação imediata e clara da diversidade dos resultados obtidos com uma síntese teórica globalizante, aceitando a existência de dimensões de mistério na realidade estudada.

c) Maior busca de entendimento das dimensões inconscientes, afetivas, míticas e religiosas dos atores sociais envolvidos, não se concentrando assim nas motivações conscientes e nos discursos explícitos.

d) A importância de se explicitar o projeto utópico e a motivação pessoal do pesquisador e dos educadores envolvidos. Educação popular só tem sentido a partir de uma utopia social e esta atravessa o conhecimento gerado. Como ela não é mais uniforme, precisa ser expressa.

e) Esforço pelos pesquisadores de abertura a outras formas de leitura da realidade estudada através da relativização do próprio projeto utópico e modelo de conhecimento.

f) Limitação intensa do envolvimento militante com a intervenção social estudada, assumindo muito mais papel de análise da ação desenvolvida pelos diversos outros atores sociais envolvidos e restringindo a sua própria ação a subgrupos e aspectos delimitados" (Vasconcelos, 1998, p. 18). 
sional, tal postura dificulta a chegada ao saber do outro" (1994, p. 3). Esta consideração nos estimula a levantar a questão: se a sistematização das diretrizes curriculares for assumida principalmente pelos funcionários da Secretaria da Educação e pelos professores da escola, tendo como referência os pressupostos e os eixos do Programa de Governo para a Educação no Rio Grande do Sul, que estratégias alternativas estão sendo desenvolvidas para se entender e se articular as propostas dos múltiplos grupos sociais que constituem os movimentos sociais populares?

Assim, ainda no segundo momento do processo constituinte, as observações sobre a prática escolar nas escolas estaduais são arroladas pela Secretaria da Educação e pelas suas 30 Delegacias de Ensino em um elenco de itens (cf. Estado/RS, 2000a, p. 20-74). Não há dúvida de que estes sejam indicadores importantes de eventos cotidianos que ocorrem no sistema de ensino. Mas em que medida revelam os interesses dos observadores e em que medida são reconhecidos os pontos de vista dos múltiplos sujeitos que tecem a comunidade educativa? E, na tentativa de tematizar e teorizar sobre a "prática" (cf. Estado/RS, 2000b), quais as chaves de interpretação privilegiadas? Como se explicitam e se afirmam os saberes, as categorias e as lógicas desenvolvidas pelos grupos populares? Tais questões podem talvez orientar uma reflexão atenta sobre os significados consolidados nos Princípios $e$ Diretrizes para a Educação Pública Estadual (Estado/RS, 2000f) a partir de seu processo de construção e de implementação.

\section{Novos olhares, novas conexões, novas possibilidades de problematização}

As questões levantadas não devem ser entendidas como contestação dos propósitos, das estratégias e dos resultados deste movimento. São indagações que podem interpelar os sujeitos, envolvidos neste processo de reformulação curricular instituído pela Constituinte Escolar do Rio Grande do Sul, na busca de ver o que ainda não foi visto e dizer o que ainda não foi dito.

A análise deste processo, através dos documen- tos produzidos, revela o hibridismo de um discurso oficial-alternativo. Tal paradoxo nos estimula a repensar sobretudo nossos modelos e nossas lógicas de interpretação da realidade social. A lógica binária e de oposição não é suficiente para interpretar as conexões complexas e dinâmicas que se estabelecem entre os sujeitos, os processos e os dispositivos que estão produzindo estas práticas discursivas. Só a partir de uma perspectiva complexa é possível compreender os limiares (os limites e as possibilidades) de um processo oficial que pretende promover, paradoxalmente, a inserção dos movimentos sociais alternativos na formulação e no controle das diretrizes curriculares da escola pública. Num processo histórico em que estes movimentos sociais têm sido sistematicamente subjugados no cenário político do Estado, tal movimento constituinte pode implicar em novos processos de sujeição dos movimentos sociais populares, à medida que a complexidade dos agentes envolvidos e a dinamicidade de suas reivindicações sejam interpretadas e elaboradas de maneira reducionista pelos dispositivos de participação disponíveis. Mas, ao mesmo tempo, pode significar a abertura de novos espaços de participação ativa de setores das classes populares na formulação de políticas públicas no campo da educação.

Victor Valla, buscando lógicas que ajudem entender os paradoxos encontrados nas práticas de educação popular, retoma o trabalho de Marília Spósito. A autora de A ilusão fecunda levanta a hipótese de que a ascensão social da população pela escola pública seria uma ilusão, mas uma ilusão fecunda. Embora seja possível hoje em dia perceber que não há garantia de melhoria de vida para alguém que completou os estudos do primeiro grau, mesmo assim, os esforços, tanto dos indivíduos, como também dos movimentos populares, trariam muitos benefícios, não somente entre as classes populares, mas entre os mediadores também. "Lutar por uma escola pública de qualidade, por uma saúde pública de atenção universal e de qualidade, buscar eleger um candidato progressista - são exemplos de possíveis ilusões fecundas, onde o objetivo final pode não estar no horizonte, mas cujo processo indicaria avanços em direção à 
democracia e à cidadania” (Valla, 1998, p. 5). Nesta perspectiva, será também possível compreender a fecundidade dos sonhos que movimentos e mediadores alimentam na Constituinte Escolar do Rio Grande do Sul.

REINALDO MATIAS FLEURI é doutor em educação e professor titular na Universidade Federal de Santa Catarina. Coordena o núcleo Mover "Educação Intercultural e Movimentos Sociais". E-mail:mover@ced.ufsc.br

\section{Referências Bibliográficas}

ALMEIDA, Adir da Luz, (1994). Pontos para um debate: participação ativa e a produção de sujeitos coletivos. In: REUNIÃO ANUAL DA ANPEd, 17ª , 1994, Caxambu (MG). Resumo in Boletim da ANPEd: Programação, resumo dos trabalhos e comunicações. Caxambu: ANPEd.

ABBOTT, E.A., (1990). Flatlândia. Milano: Mursia.

BARRETO, Elba Siqueira de Sá, (1998). Tendências recentes do currículo do ensino fundamental no Brasil. In: . Os currículos do ensino fundamental para as escolas brasileiras. Campinas, SP: Autores Associados, São Paulo: Fundação Carlos Chagas, p. 5-42.

BATESON, Gregory, (1976). Verso un'ecologia della mente. Milano: Adelphi, [1972]. [Steps to an Ecology of Mind]. Trad. ital. Giuseppe Longo.

(1986). Mente e natureza. A unidade necessária. Rio de Janeiro: Francisco Alves [1979]. (Trad. ital. 1984). [Mind and Nature: a necessary unity]. Trad. bras. Claudia Gerpe.

(1997). Una sacra unità. Altri passi verso un'ecologia della mente. Milano: Adelphi, 1997 [1991]. [A sacred unity. Further steps to na ecology of mind]. Trad. ital. de Giuseppe Longo.

BOCCHI, G., CERUTI, M. (a cura di), (1985). La sfida della complessità. Milano: Feltrinelli.

CANCLINI, Nestor Garcia, (1983). As culturas populares no capitalismo. São Paulo: Brasiliense.

COIMBRA, Cecília Maria Bouças, (1992). Gerentes da ordem: a subjetividade dos anos 60 e 70 no Brasil. Doutorado em Educação. Faculdade de Educação da Universidade de São Paulo.
CORAZZA, Sandra, (2000). Currículos alternativos/oficiais: o(s) risco(s) do hibridismo. In: REUNIÃO ANUAL DA ANPEd, $23^{\mathrm{a}}$, 2000, Caxambu (MG). Caxambu: ANPEd.

COSTA, Marisa Vorraber, (1998a). Currículo e Política Cultural. In: . (org.). O currículo nos limiares do contemporâneo. Rio de Janeiro: DP\&A. (org.) (1998b). Educação popular hoje. São Paulo: Loyola.

ESTADO do Rio Grande do Sul. Secretaria da Educação, (2000a). Caderno 4 da Constituinte Escolar. Sistematização do $2^{\circ}$ Momento (Estudo da realidade e resgate de práticas pedagógicas). Porto Alegre, abr. s.p. [80p.].

ESTADO do Rio Grande do Sul. Secretaria da Educação, (2000b). Cadernos Temáticos da Constituinte Escolar. Porto Alegre, maio. v. 24

ESTADO do Rio Grande do Sul. Secretaria de Estado da Educação, (2000c). Regimento da conferência estadual da educação. Porto Alegre, jun. 16p.

ESTADO do Rio Grande do Sul. Secretaria de Estado da Educação, (2000d). Texto base das pré-conferências municipais $e$ microrregionais da educação. Porto Alegre, jul. 22p.

ESTADO do Rio Grande do Sul. Secretaria de Estado da Educação, (2000e). Construção da escola democrática e popular Texto base para a conferência regional da educação. Porto Alegre, jul. 36p.

ESTADO do Rio Grande do Sul. Secretaria de Estado da Educação, (2000f). Princípios e diretrizes para a educação pública estadual. Porto Alegre: Corag. 66p.

FANTIN, Maristela, (1996). Construção de Sujeitos e Educação Popular. In: REUNIÃO ANUAL DA ANPEd, 19ª 1996, Caxambu-MG. Resumo in Boletim da ANPEd: Programação, resumo dos trabalhos e comunicações. Caxambu: ANPEd. Trabalho publicado em disquete, $15 \mathrm{p}$.

GINZBURG, C., (1987). O queijo e os vermes: o cotidiano e as idéias de um moleiro perseguido pela Inquisição. São Paulo: Companhia das Letras.

GONSALVES, Elisa Pereira, (1997). Educação popular: entre a modernidade e a pós-modernidade. In: REUNIÃO ANUAL DA ANPEd, 20a , 1997, Caxambu (MG). Resumo in Boletim da ANPEd: Programação, resumo dos trabalhos e comunicações. Caxambu: ANPEd. Trabalho publicado em disquete, 15p. 
GUATTARI, Félix, ROLNIK, Sueli, (1986). Micropolítica; cartografias do desejo. Petrópolis: Vozes.

MARTINS, José de Souza, (1989). Caminhada no Chão da Noite; emancipação política e libertação nos movimentos sociais do campo. São Paulo: Hucitec.

MELE, Ortensia, (1994). Attorno ad un buco. In: MOVIMENTO DI COOPERAZIONE EDUCATIVA, Le chiavi di vetro. Firenze: La Nuova Italia, p. 213-238.

MORIN, Edgar, (1985). Le vie della complessità. In: BOCCHI G., CERUTI M. (a cura di). La sfida della complessità. Milano: Feltrinelli. p. 49-60.

RODRIGUES, Daniel Álvares, (1997). Escola Quilombo dos Palmares - Uma Experiência de Educação Popular: A Crise e Crítica aos Paradigmas. In: REUNIÃO ANUAL DA ANPEd, 20a, 1997, Caxambu (MG). Resumo in Boletim da ANPEd: Programação, resumo dos trabalhos e comunicações. Caxambu: ANPEd. Trabalho publicado em disquete, 15p.

SADER, Eder, (1988). Quando novos personagens entraram em cena. Rio de Janeiro: Paz e Terra.

SEVERI, Vittorio, ZANELLI, Paolo, (1990). Educazione, complessità e autonomia dei bambini. Firenze: Nuova Italia.
SPÓSITO, Marília Pontes, (1993). A ilusão fecunda: A luta por educação nos movimentos populares. São Paulo: HUCITEC.

VALLA, Victor Vincent, (1994). A crise de interpretação é nossa: procurando compreender a fala das classes subalternas. In: REUNIÃO ANUAL DA ANPEd, 17ª, 1994, Caxambu- MG. Resumo in Boletim da ANPEd: Programação, resumo dos trabalhos e comunicações. Caxambu: ANPEd, p. 176. Trabalho manuscrito [18p.].

, (1998a). Movimentos sociais, educação popular e intelectuais: entre algumas questões metodológicas. In: FLEURI (org.). Intercultura e Movimentos Sociais. Florianópolis: MOVER/NUP. p. 187-200.

(1998b). A revalorização da educação popular numa conjuntura de crise. In: REUNIÃO ANUAL DA ANPEd, $21^{\text {a }}$, 1998b, Caxambu (MG). Resumo in Boletim da ANPEd: Programação, resumo dos trabalhos e comunicações. Caxambu: ANPEd. Trabalho publicado em disquete, 15p.

VASCONCELOS, Eymard Mourão, (1998). Educação popular e o programa de saúde da família. In: REUNIÃO ANUAL DA ANPEd, 21a , 1998, Caxambu (MG). Resumo in Boletim da ANPEd: Programação, resumo dos trabalhos e comunicações. Caxambu: ANPEd. Trabalho publicado em disquete, 15p. 
The appropriations of Pierre Bourdieu's work in the brazilian educational field

Based on research carried out in 20 specialised educational periodicals, published between 1971 and 2000, the present text analyses the forms of appropriation from Pierre Bourdieu's work in the field of Brazilian education. The set of 355 articles published in those periodicals that make reference to the sociologist constitutes the basic corpus for the analysis of the peculiarities of the Brazilian interpretations of this author.

Marcus Vinicius da Cunha

John Dewey e o pensamento educacional brasileiro: a centralidade da noção de movimento

$\mathrm{O}$ trabalho analisa artigos publicados em periódicos educacionais brasileiros entre 1930 e 1960, cujos temas são educação, democracia, filosofia, ciência e verdade, entre outros, desenvolvidos segundo concepções de Dewey. Em todos, ocupam posição central as noções de mudança e transformação, em oposição a estabilidade, fixidez e permanência. O objetivo é mostrar a relevância da noção de mundo em movimento, tanto para os brasileiros quanto para Dewey.

John Dewey and the brazilian educational thinking: the main position of the concept of change This paper analyses some articles published by educational journals in Brazil between 1930 and 1960, whose subjects are education, democracy, philosophy, science, truth and others, developed according to Dewey's ideas. In all of them, the main concept is the transformation of things, in opposition to steady. The central intent is to show the change of world like a key concept to the brazilian authors, as such as to Dewey.

\section{Sandra Mara Corazza}

Currículos alternativos/oficiais: o(s) risco(s) do hibridismo

$\mathrm{O}$ artigo enfatiza similaridades discursivas entre os PCNs do Ministério da Educação do Brasil, tidos como currículo oficial, e o Movimento Constituinte Escolar do governo petista do Rio Grande do Sul, proposto como currículo alternativo. Reflete sobre o que vem acontecendo com nossos currículos alternativos críticos, que acabam propondo quase a mesma educação que a do Governo Federal. Argumenta que, em função desse hibridismo, precisamos desfazer o risco de ligação, produzir e praticar currículos que ainda não existem, inventar mais uma vez a diferença.

\section{Alternative-official curricula: the} risk(s) of hybridism

The article stresses the discursive similarities between the National Curricula Parameters (PCN) established by the Brazilian Ministry of Education, considered the official curriculum, and the School Assembly Movement inspired by the Workers' Party state government in Rio Grande do Sul, proposed as an alternative curriculum. It discusses what has been happening with our critical alternative curricula which end up proposing almost the same education as that of the Federal Government. It forwards the argument that, as a consequence of this hybridism, we need to dispel the ambiguity, by producing and putting into practice curricula which do not yet exist and to invent once more the difference.

Reinaldo Matias Fleuri

Entre o oficial e o alternativo em propostas curriculares: para além do hibridismo

$\mathrm{O}$ texto discute a relação entre o oficial e o alternativo no discurso da Constituinte Escolar (1999-2000), pro- movida pelo governo do estado do Rio Grande do Sul (BR). Traz contribuições de pesquisadores em educação popular para interpelar os sujeitos (em particular os movimentos sociais populares e as instituições estatais) e discutir a metodologia utilizada neste processo de reformulação curricular. Enfatiza a importância da perspectiva complexa para se compreender os limites e as possibilidades de um processo oficial que pretende promover, paradoxalmente, a inserção dos movimentos sociais alternativos na formulação e no controle das diretrizes curriculares da escola pública.

Between the official and the alternative in curricular proposals: beyond hybridism

The text discusses the relationship between the official and the alternative discourse used in the School Assembly (1999-2000), sponsored by the state government of Rio Grande do Sul, in the south of Brazil. It presents contributions from researchers in the field of Popular Education with the purpose of inciting the subjects (specifically the popular social movements and state institutions) to reflect upon their practices and to discuss the methodology employed in this process of curriculum reform. It also emphasizes the significance of the complex perspective for understanding the limits and possibilities of an official process aimed at promoting, paradoxically, the participation of the alternative social movements in the formulation and control of curricular guidelines for the state school.

Creso Franco

O SAEB - Sistema de Avaliação da Educação Básica: potencialidades, problemas e desafios

Baseado em contribuição preparada no contexto da Comissão de Especialistas, 